\title{
The short-term physiological impact of switching reusable silicone hydrogel wearers into a hydrogel daily disposable multifocal
}

This article was published in the following Dove Press journal: Clinical Ophthalmology

\author{
Amir M Moezzi ${ }^{1}$ \\ Jalaiah Varikooty' \\ Doerte Luensmann' \\ Marc-Matthias Schulze \\ Alison $\mathrm{Ng}^{\prime}$ \\ Thomas Karkkainen ${ }^{2}$ \\ Jing $\mathrm{Xu}^{2}$ \\ Lyndon Jones \\ 'Centre for Ocular Research \& Education \\ (CORE, formerly Centre for Contact \\ Lens Research), School of Optometry \\ and Vision Science, University of \\ Waterloo, Waterloo, Ontario, Canada; \\ ${ }^{2}$ Research and Development, Johnson \& \\ Johnson Vision, Jacksonville, FL, USA
}

Correspondence: Amir M Moezzi Centre for Ocular Research \& Education (CORE), School of Optometry and Vision Science, University of Waterloo, 200

University Avenue West, Waterloo,

Ontario, Canada, N2L 3GI

Tel +I 5 I 9884567 Ext 3502I

Fax +15198884303

Email ammoezzi@uwaterloo.ca
Purpose: To evaluate ocular physiological responses to etafilcon A multifocal (etMF) daily disposable (DD) lenses after 4 weeks of wear, when switching from habitual silicone hydrogel ( $\mathrm{SiHy}$ ) daily wear.

Method: A single-arm, open-label, bilateral dispensing study was conducted in 39 habitual spherical SiHy wearers (14 hyperopes; 25 myopes). Clinical visits occurred with habitual SiHy (control) at baseline and after 4 weeks of etMF DD open-eye lens wear at exit. Objective limbal/bulbar hyperemia using the Oculus K5M (0-4) and subjective grading of lid wiper epitheliopathy (LWE) (0-4) were tested for non-inferiority (NI), using a margin of 1 grade. Corneal thickness along a $10 \mathrm{~mm}$ cord was measured using the Visante OCT and tested for NI using a $30 \mu \mathrm{m}$ margin. Corneal staining area was graded $(0-100 \%)$.

Results: The least-square mean differences (LSMD) and 95\% confidence interval (95\% CI) between etMF DD and habitual SiHy in central and peripheral corneal thickness $(\mu \mathrm{m})$ were $3.64(-2.0,9.29)$ and $3.0(-7.72,13.72)$ in hyperopic, and $3.56(-0.66,7.78)$ and $6.40(-1.62$, $14.42)$ in myopic subjects. The LSMD $(95 \% \mathrm{CI})$ for bulbar and limbal hyperemia were -0.08 $(-0.19,0.02)$ and $-0.01(-0.12,0.09)$ in hyperopes, and $0.04(-0.03,0.12)$ and $0.04(-0.04$, $0.11)$ in myopes. The LSMD $(95 \%$ CI $)$ for LWE were $0.11(-0.39,0.60)$ and $0.30(-0.07$, 0.67 ) for hyperopes and myopes, respectively.

Conclusions: No clinically significant differences in a variety of physiological responses were found when habitual reusable SiHy daily wear subjects were refitted into hydrogel etMF, when the subjects were followed for 4 weeks.

Keywords: corneal swelling, corneal thickness, limbal hyperemia, oxygen transmissibility, presbyopia, OCT

\section{Introduction}

Soft contact lenses act as a barrier to oxygen transport to the cornea, limiting the availability of atmospheric oxygen for normal corneal metabolism. ${ }^{1}$ Corneal swelling occurs as a result of stromal lactic acid accumulation from increased corneal anaerobic metabolic activity, ${ }^{2}$ and it is widely accepted as the main index of corneal oxygen deficiency. ${ }^{1,3,4}$ The inverse relationship between soft lens oxygen transmissibility and the amount of induced corneal thickening is well established in the literature. ${ }^{5}$ Maximum corneal swelling occurs in overnight contact lens (CL) wear due to further oxygen deprivation under a closed lid. ${ }^{6}$

Highly oxygen permeable silicone hydrogel (SiHy) soft lenses were commercialized at the end of the last millennium, with the initial intention of reducing the rate of adverse 
events seen with conventional hydrogel lenses in extended wear. ${ }^{7}$ However, the potential promise of a reduced incidence of microbial keratitis (MK) with SiHy lenses has not been fulfilled and the rates of MK have remained largely unchanged. ${ }^{8}$ Despite the failure of SiHy lenses to alter MK rates during overnight wear, SiHy lenses were rapidly adopted for use on a daily wear basis and now account for over $65 \%$ of the new fits in many markets around the world ${ }^{9}$ and have progressively replaced reusable hydrogel lenses as the first choice material for daily wear. This rapid increase in the use of SiHy lenses has been attributed to their perceived superior clinical performance, largely due to their higher oxygen transmissibility $\left(\mathrm{Dk} / \mathrm{t}\right.$; unit $\left.=\left[\mathrm{cm} \mathrm{mL} \mathrm{O}_{2}\right] /[\mathrm{mL} \mathrm{s} \mathrm{mmHg}]\right)$ producing fewer signs of both acute and chronic hypoxia. These clinical signs include corneal swelling, limbal hyperemia, myopic creep, epithelial microcysts and stromal striae. ${ }^{10-15}$ Despite these advantages, a recent review ${ }^{16}$ of lens-related corneal infiltrative events (CIEs) pointed to several studies that showed an approximately two times higher relative risk of developing CIEs with reusable SiHy lenses compared to hydrogel lenses. ${ }^{17-19}$

Technological advances facilitated by the high $\mathrm{Dk} / \mathrm{t}$ of SiHy materials present potential opportunities for expanding the use of contact lenses in areas that have exhibited limited uptake in the past, such as astigmatism and presbyopia, ${ }^{20}$ where the thicker designs resulted in hypoxia. Indeed, many companies now offer both toric and presbyopic designs in SiHy materials and these options continue to increase in popularity., ${ }^{9,21-23}$ However, SiHy materials have been associated with reduced in-eye wetting in some patients with poor quality tear films ${ }^{24}$ and may also deposit tear film lipids to a greater extent than hydrogels. ${ }^{25-27}$ Thus, while SiHy materials have benefits from an oxygen transport perspective, the material may not be as clinically acceptable in an older individual with a dry eye or inferior quality tear film, ${ }^{28,29}$ and it could be argued that these patients may be more optimally fitted with a hydrogel material. Besides, some patients may have a comfort preference for hydrogel lenses, ${ }^{30,31}$ likely due to higher hydrophilicity and/or lower modulus s2-35 $^{35}$ of hydrogel materials. It is also worth noting that, in clinical situations, various multifocal (MF) optical designs exist, ${ }^{36-43}$ with some of them being unique to certain lens materials. However, not every patient is successful with every MF design. ${ }^{41}$ This will inevitably result in patient preference for certain MF designs, some of which may only be available in hydrogel materials.
A new multifocal daily disposable CL (1-Day Acuvue Moist Multifocal ${ }^{44,45}$ is available commercially. This lens varies in design depending upon the distance prescription and age, with a change in each design to acknowledge the change in pupil size that occurs with age and prescription. ${ }^{46,47}$ This lens design is currently only available in a hydrogel material (etafilcon A, 58\% water content) that is replaced on a daily disposable (DD) basis, and thus concerns may exist regarding its oxygen performance. This is particularly relevant for wearers who may have previously been wearing a SiHy MF but who prefer the visual performance of the hydrogel lens.

The purpose of this pilot study was to investigate the ocular physiological impact of switching existing wearers of SiHy lenses into this new hydrogel DD MF CL (study test lens/etMF), over the course of four weeks.

\section{Materials and methods}

This study was performed in compliance with the ethical principles of the Declaration of Helsinki and Good Clinical Practice (GCP). The study received ethics clearance through the Office of Research Ethics (ORE) at the University of Waterloo. Written informed consent was obtained from all subjects prior to enrolment in the study.

\section{Study design and masking}

This was a pilot, prospective, single-arm, open-label, 4-week bilateral eye, dispensing study. There was no wash-out period in this study, and the study design was unable to accommodate either randomization or masking. The study design was set up to mimic the process that would most likely occur in a clinical practice, in which a SiHy MF wearer who was exhibiting performance issues with their lenses (either visually or due to deposition/wetting) would be offered an opportunity to be directly refitted into the hydrogel MF DD option.

\section{Subjects and sample size justification}

A sample size for this study was not calculated due to the pilot nature of the study and the fact that no published studies to date have switched presbyopic SiHy wearers into a hydrogel lens.

To be eligible, subjects were required to be between the ages of 40 and 70 years old and to be current spherical SiHy lens wearers (not necessarily SiHy MF) with healthy eyes, vertexed spherical equivalent distance correction between +3.50 and $-5.50 \mathrm{D}$, subjective refraction cylinder of $\leq 0.75$ $\mathrm{D}$, reading addition of $+0.75 \mathrm{D}$ to $+2.50 \mathrm{D}$, and distance and 
near best correctable visual acuity of $\log$ MAR 0.1 or better in each eye. Forty-four habitual wearers of SiHy lenses were initially enrolled, from which three subjects were ineligible (screen failures who did not meet the study inclusion/exclusion criteria) and two subjects were eligible but withdrew consent before assignment of the study lens. Thirty-nine eligible subjects (14 hyperopes; 25 myopes, mean \pm Std age of $57.6 \pm 7.4$ and $52.8 \pm 6.3$ years, respectively) were dispensed with the test article and all completed the study. Demographics of the study participants are listed in Table 1.

\section{Lenses and solutions}

Eligible subjects attended the baseline visit while wearing a fresh pair of their habitual SiHy lenses (control). The habitual lenses included various currently marketed SiHy lenses, as previous research did not show an evidence of any differences in physiological performance of SiHy

Table I Subject demographics

\begin{tabular}{|c|c|c|c|c|}
\hline \multicolumn{5}{|c|}{ Hyperopes } \\
\hline & Completed & $\begin{array}{l}\text { Total } \\
\text { dispensed }\end{array}$ & $\begin{array}{l}\text { Total not } \\
\text { dispensed }\end{array}$ & $\begin{array}{l}\text { Total } \\
\text { enrolled }\end{array}$ \\
\hline \multicolumn{5}{|c|}{ Gender n (\%) } \\
\hline Female & 13 (92.9) & $13(92.9)$ & I $(100)$ & $14(93.3)$ \\
\hline Male & I (7.I) & I (7.I) & $0(0.0)$ & I (6.7) \\
\hline \multicolumn{5}{|l|}{ Age } \\
\hline $\mathrm{n}$ & 14 & 14 & I & 15 \\
\hline Mean & 57.6 & 57.6 & 57.0 & 57.6 \\
\hline Std & 7.43 & 7.43 & - & 7.16 \\
\hline Median & 58.0 & 58.0 & 57.0 & 58.0 \\
\hline Min & 45.0 & 45.0 & 57.0 & 45.0 \\
\hline Max & 67.0 & 67.0 & 57.0 & 67.0 \\
\hline \multicolumn{5}{|c|}{ Myopes } \\
\hline & Completed & $\begin{array}{l}\text { Total } \\
\text { dispensed }\end{array}$ & $\begin{array}{l}\text { Total not } \\
\text { dispensed }\end{array}$ & $\begin{array}{l}\text { Total } \\
\text { enrolled }\end{array}$ \\
\hline \multicolumn{5}{|c|}{ Gender n (\%) } \\
\hline Female & $19(76.0)$ & $19(76.0)$ & $2(100)$ & 21 (77.8) \\
\hline Male & $6(24.0)$ & $6(24.0)$ & $0(0.0)$ & $6(22.2)$ \\
\hline \multicolumn{5}{|l|}{ Age } \\
\hline$n$ & 25 & 25 & 2 & 27 \\
\hline Mean & 52.8 & 52.8 & 58.0 & 53.2 \\
\hline Std & 6.33 & 6.33 & 8.49 & 6.46 \\
\hline Median & 51.0 & 51.0 & 58.0 & 52.0 \\
\hline Min & 43.0 & 43.0 & 52.0 & 43.0 \\
\hline $\operatorname{Max}$ & 65.0 & 65.0 & 64.0 & 65.0 \\
\hline
\end{tabular}

Abbreviations: Std, standard deviation; Min, minimum; Max, maximum. lenses in daily wear based on their $\mathrm{Dk} / \mathrm{t}^{48}$ All habitual SiHy lenses were used on a reusable format, with replacement periods being for 1 month or less, with the exception of 1 subject in the hyperopic and 2 subjects in the myopic group, who were wearing DD SiHy lenses (Table 2).

Following the initial visit, subjects were then switched to the test lens/etMF (1-Day Acuvue Moist Multifocal lenses, Table 3) for DD wear for the next $28 \pm 4$ days. There were no contact lens care solutions or any other contact lens care products used in this study. The use of rewetting drops was not permitted in this study to avoid any confounding effects on the study outcome variables.

\section{Procedures}

The study included a screening visit, a baseline visit with a fresh pair of habitual SiHy lenses, followed by bilateral dispensing of etMF lenses. Slit-lamp examination of the cornea, including assessments for the presence of any microcysts and/or striae, was conducted at each study visit. Study lenses were worn on a DD basis for the next four weeks, after which subjects returned for a final visit. The 2 clinical study visits occurred after $6 \mathrm{hrs}$ of open-eye lens wear with habitual $\mathrm{SiHy}$ (control) at both the baseline (Bl) visit and after the 4 weeks DD wear of the study lenses. Each subject was instructed to wake at least $2 \mathrm{hrs}$ before lens insertion on the morning of both visits to minimize any residual corneal swelling from overnight eye closure. $^{49,50}$

Central corneal thickness immediately after lens removal was measured in the right eye using the Visante optical coherence tomographer (OCT; Carl Zeiss Meditec, Jena, Germany) pachymetry map for corneal thickness data along the horizontal meridian, within a range from $-5 \mathrm{~mm}$ to $+5 \mathrm{~mm}$ around the center of the cornea, using a procedure previously reported. ${ }^{51}$ These measurements comprised the average data for the central 0-2 $\mathrm{mm}$ cornea, and both temporal and nasal 2-5 $\mathrm{mm}$ peri-central, $5-7 \mathrm{~mm}$ transitional/midperipheral and $7-10 \mathrm{~mm}$ peripheral zones along the horizontal meridian. The mean corneal thickness at each corneal zone (except central) was derived from averaging the temporal and nasal OCT measurements for that zone. The Visante OCT calibration was automatically conducted when the instrument was turned on each study day, using the self-verification test tool provided by the manufacturer.

In addition to corneal thickness, the physiological impact of the lenses was also assessed at the two clinical visits by a) objective grading of bulbar and limbal hyperemia; b) subjective grading of corneal staining area and c) grading of the 
Table 2 Habitual contact lenses

\begin{tabular}{|l|l|l|l|}
\hline Habitual SiHy contact lenses & Number of hyperopes & Number of myopes & Total \# of subjects \\
\hline Acuvue Oasys for Presbyopia & - & 3 & 3 \\
\hline Acuvue Oasys with Hydraclear Plus & - & 4 & 4 \\
\hline Air Optix Aqua & 2 & 2 & 4 \\
\hline Air Optix Aqua Multifocal & 5 & 4 & 9 \\
\hline Air Optix Night and Day Aqua & - & I & I \\
\hline Biofinity Multifocal & 2 & 4 & 6 \\
\hline Clariti I Day Multifocal & $\mathrm{I}$ & $\mathrm{I}$ & 2 \\
\hline Dailies Total I & - & $\mathrm{I}$ & $\mathrm{I}$ \\
\hline PureVision & $\mathrm{I}$ & $\mathrm{I}$ & 2 \\
\hline PureVision Multifocal & 2 & 2 & 4 \\
\hline PureVision 2 & - & $\mathrm{I}$ & $\mathrm{I}$ \\
\hline PureVision 2 for Presbyopia & $\mathrm{I}$ & $\mathrm{I}$ & 2 \\
\hline Total & $\mathrm{I}$ & 25 & 39 \\
\hline
\end{tabular}

lid wiper epitheliopathy (LWE). Bulbar and limbal hyperemia were graded using the Oculus K5M (Oculus, Wetzlar, Germany) device (0-4 scale, in 0.1 increments). ${ }^{52}$ Corneal

Table 3 Study lens parameters

\begin{tabular}{|l|l|}
\hline Name & $\begin{array}{l}\text { I-Day Acuvue } \\
\text { Multifocal Brand } \\
\text { (Spherical Lenses) }\end{array}$ \\
\hline Manufacturer & Johnson \& Johnson Vision \\
\hline Lens material & etafilcon A \\
\hline $\begin{array}{l}\text { Nominal base curve } \\
\left.\text { mm (at } 22^{\circ} \mathrm{C}\right)\end{array}$ & 8.40 \\
\hline $\begin{array}{l}\text { Nominal diameter } \\
\left.\text { mm (at 22 }{ }^{\circ} \mathrm{C}\right)\end{array}$ & 14.3 \\
\hline Distance powers (D) & +4.00 to -6.00 in $0.25 \mathrm{D}$ steps \\
\hline Add power & Low, Mid, High \\
\hline Water content & $58 \%$ \\
\hline $\begin{array}{l}\text { Nominal center } \\
\text { thickness mm } \\
\text { (at }-3.00 \mathrm{D})\end{array}$ & 0.084 \\
\hline $\begin{array}{l}\text { Oxygen } \\
\text { transmissibility (Dk/t) }\end{array}$ & 25.5 \\
\hline Modality & Daily disposable \\
\hline
\end{tabular}

staining by sodium fluorescein was assessed based on percentage area $(0-100 \%)$ by recording the area of staining (graded in $1 \%$ increments) for 5 zones of the cornea. ${ }^{53}$ Observations were made using a Wratten 12 barrier filter. ${ }^{54}$ LWE (sodium fluorescein) was graded after carefully everting the upper lid $(0-4$ scale, integer steps, where $0=$ no staining, $1=1 \%$ to $25 \%, 2=26 \%$ to $50 \%, 3=51 \%$ to $75 \%$ and $4=76 \%$ to $100 \%$ staining of wiper area).

\section{Data analysis}

All data summaries and statistical analyses were performed using the SAS software Version 9.4 (SAS Institute, Cary, NC). All planned analysis for this study was conducted with an overall type I error rate of 5\%.

Corneal thickness, limbal and bulbar hyperemia, and LWE were analyzed separately using a linear mixed model. Comparisons between the test lens and habitual lens were carried out using 95\% confidence intervals constructed around least-square means (LSM) differences (follow-up minus baseline values) from the linear mixed model. For corneal thickness, comparisons between the habitual SiHy lenses and the test Multifocal lens were derived for the respective location (Central, Peri-Central, Mid-peripheral, Peripheral) using the corresponding simultaneous confidence intervals (CIs) of least-square means differences (day 28 - baseline), which were calculated with $95 \%$ confidence. A test for non-inferiority of the test lens 


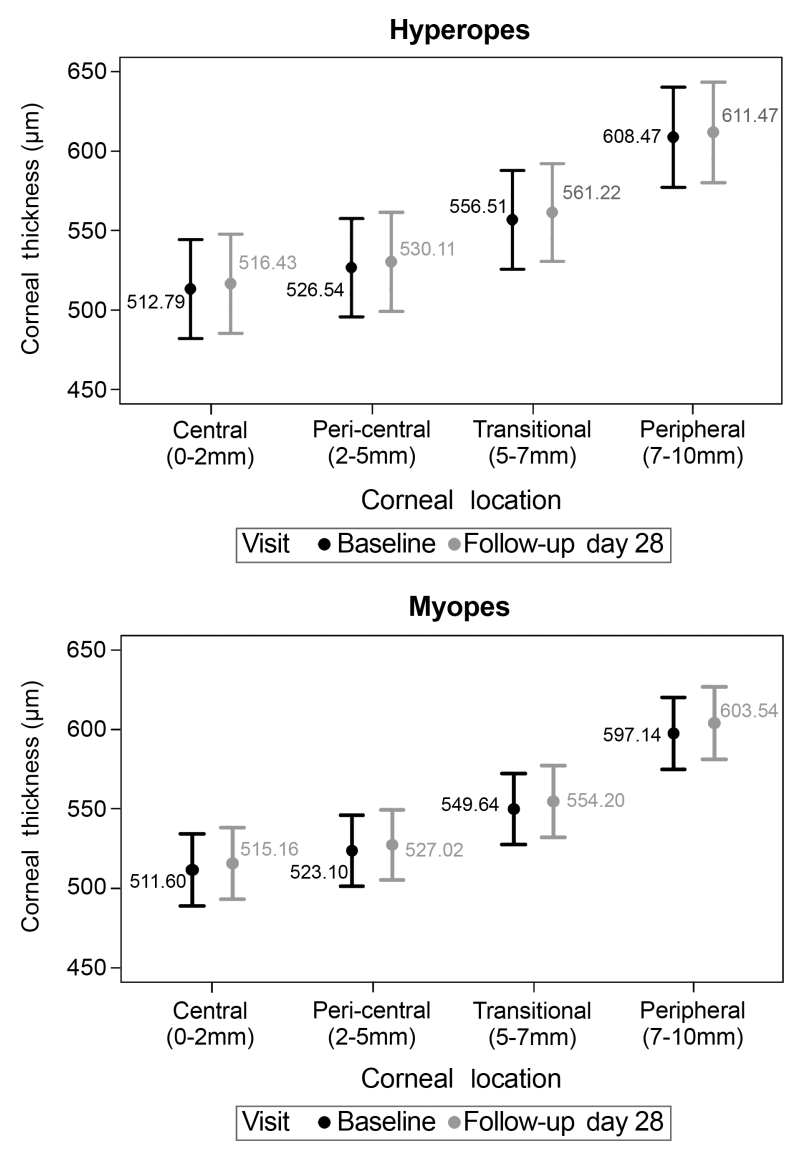

Figure I Open-eye corneal thickness (LS mean $\pm \mathrm{Cl}$ ) across the cornea (OCT) in hyperopes (top) and myopes (bottom) (overall values are not shown to prevent crowding).
(etMF DD on day 28) relative to the control lens (habitual SiHy at baseline) was carried out by comparing the upper limit confidence interval of the corresponding LSM difference to the $30 \mu \mathrm{m}$ margin. If the upper limit was below 30 $\mu \mathrm{m}$, non-inferiority was concluded. If the upper limit was below $30 \mu \mathrm{m}$ and the lower limit was above $-30 \mu \mathrm{m}$ then clinical equivalence was concluded. Similarly, the noninferiority analysis was conducted for limbal and bulbar hyperemia and LWE using a 1 grade margin. For conjunctival hyperemia and lid wiper epitheliopathy, the noninferiority was concluded if the upper confidence limit of LSM difference was less than 1 grade. For mean corneal staining area (\%), a test for non-inferiority was planned but could not be conducted due to there being $0 \%$ corneal staining in the majority of cases. Therefore, descriptive analyses were used to compare corneal staining between the test and control lenses.

\section{Results}

The study test/etMF DD lenses were worn for a mean \pm std wearing time of $11.4 \pm 2.5 \mathrm{hrs} /$ day for $26.7 \pm 1.8$ days during the study period. After 4 weeks of open-eye wear, no clinically significant differences between any of the study outcome variables for either hyperopes or myopes were found when switching from habitual SiHy CLs at baseline into the etMF DD lenses. In addition, slit-lamp examination of the

Table 4 Least square (LS) mean difference estimates and 95\% confidence intervals (Cl) of corneal thickness ( $\mu \mathrm{m})$ along horizontal meridian measured with OCT

\begin{tabular}{|c|c|c|c|c|c|c|c|}
\hline Location & Subject group & $\begin{array}{l}\text { LS-Mean } \\
\text { difference }\end{array}$ & StdErr & Lower Cl & Upper Cl & $\begin{array}{l}\text { Non-inferiority } \\
\text { Met? }\end{array}$ & $\begin{array}{l}\text { Equivalence } \\
\text { Met? }\end{array}$ \\
\hline \multirow[t]{3}{*}{ Central $(0-2 \mathrm{~mm})$} & Hyperopes & 3.643 & 2.3281 & -2.000 & 9.286 & Yes & Yes \\
\hline & Myopes & 3.560 & 1.7422 & -0.663 & 7.783 & Yes & Yes \\
\hline & Overall & 3.601 & 1.4539 & 0.077 & 7.126 & Yes & Yes \\
\hline \multirow[t]{3}{*}{ Peri-central $(2-5 \mathrm{~mm})$} & Hyperopes & 3.571 & 1.8633 & -0.402 & 7.545 & Yes & Yes \\
\hline & Myopes & 3.920 & 1.3943 & 0.947 & 6.893 & Yes & Yes \\
\hline & Overall & 3.746 & 1.1636 & 1.264 & 6.227 & Yes & Yes \\
\hline \multirow[t]{3}{*}{ Transitional $(5-7 \mathrm{~mm})$} & Hyperopes & 4.714 & 2.4698 & -0.744 & 10.172 & Yes & Yes \\
\hline & Myopes & 4.560 & 1.8482 & 0.476 & 8.644 & Yes & Yes \\
\hline & Overall & 4.637 & 1.5424 & 1.229 & 8.046 & Yes & Yes \\
\hline \multirow[t]{3}{*}{ Peripheral $(7-10 \mathrm{~mm})$} & Hyperopes & 3.000 & 5.0689 & -7.722 & 13.722 & Yes & Yes \\
\hline & Myopes & 6.400 & 3.7933 & -1.624 & 14.424 & Yes & Yes \\
\hline & Overall & 4.700 & 3.1656 & -1.996 & 11.396 & Yes & Yes \\
\hline
\end{tabular}

Notes: Alpha level=0.05. Non-inferiority is established if the upper confidence limit is less than 30 microns. Equivalence is established if the upper and lower confidence limits are between \pm 30 microns.

Abbreviations: LS-Means, least-square means (Day 28 - baseline); StdErr, standard error; Cl, confidence limits. 

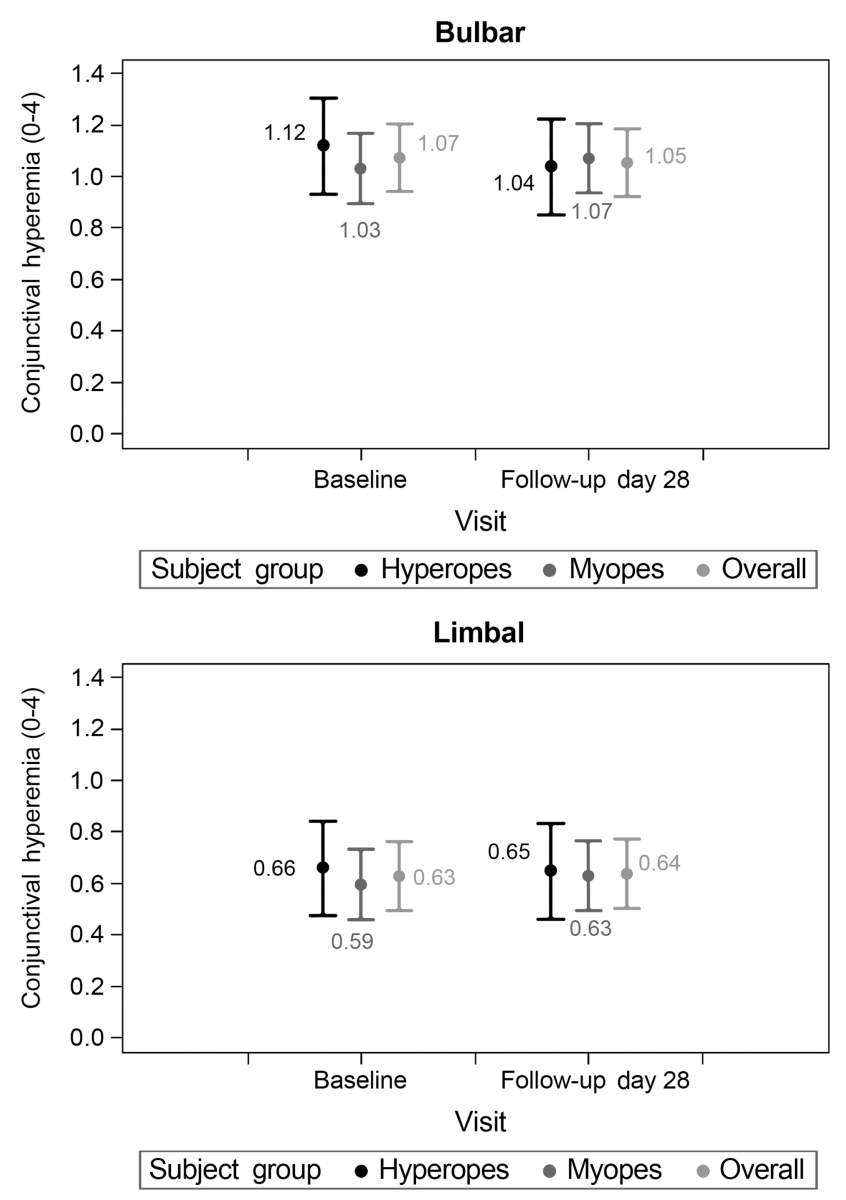

Figure 2 Open-eye objective (Oculus K5M) bulbar (top) and limbal (bottom) hyperemia (LS mean $\pm \mathrm{CI}$ ).

cornea revealed no microcysts and/or striae in any subjects at any study visits.

The test lenses were equivalent to habitual contact lenses for corneal thickness within $4 \mu \mathrm{m}$ centrally and 7 $\mu \mathrm{m}$ peripherally, which was well within the pre-stated clinical margin of $30 \mu \mathrm{m}$ in OCT measurement difference between day 28 and baseline. (Figure 1 and Table 4).

There was no significant difference within \pm 0.1 grade in objective bulbar and limbal hyperemia (which was well within the pre-stated clinical margin of 1 grade in Oculus $\mathrm{K} 5 \mathrm{M}$ measurements of bulbar and limbal conjunctival redness) between the test CL and habitual control lenses (Figure 2 and Table 5). There was also no significant difference within 0.3 grade in LWE between the test and control lenses, which was also well within the pre-stated clinical margin of 1 grade (Table 6).

There was no corneal staining in $59 \%$ of the eyes at baseline or the final visit. Similarly, $36 \%$ of the eyes at baseline and $41 \%$ of the eyes at the final visit had a graded mean staining of $\leq 8 \%$ of the total corneal area (Figure 3 , bottom). The maximum grades of mean corneal staining area were $17 \%$ of the entire corneal area in hyperopes and $5 \%$ in myopes at baseline, and $\leq 8 \%$ in both subject groups at exit (Figure 3, top and middle).

\section{Discussion}

The major clinical benefits of daily disposable lenses are their convenience and avoidance of solutions and contact lens cases. ${ }^{55,56}$ While most of the current DD options (especially in MF designs) are available in hydrogel materials, the majority of reusable contact lenses (including MF lenses) fitted to patients are silicone hydrogels. ${ }^{9}$ This study sought to determine if there were any physiological concerns over a 4-week period if existing wearers of SiHy lenses were switched into a hydrogel MF product.

Ocular physiological response to the study treatment was determined by evaluating corneal thickness, limbal and bulbar hyperemia, LWE and corneal staining. To avoid an averaging effect of the possible different ocular physiological

Table 5 Least square (LS) mean difference estimates and $95 \%$ confidence intervals (CI) of objective bulbar and limbal hyperemia by Oculus K5M

\begin{tabular}{|c|c|c|c|c|c|c|c|c|}
\hline Type & Subject group & $\begin{array}{l}\text { Alpha } \\
\text { level }\end{array}$ & $\begin{array}{l}\text { LS-Mean } \\
\text { difference }\end{array}$ & StdErr & Lower Cl & Upper Cl & $\begin{array}{l}\text { Non- } \\
\text { inferiority } \\
\text { Met? }\end{array}$ & $\begin{array}{l}\text { Equivalence } \\
\text { Met? }\end{array}$ \\
\hline Bulbar redness & $\begin{array}{l}\text { Hyperopes } \\
\text { Myopes } \\
\text { Overall }\end{array}$ & $\begin{array}{l}0.05 \\
0.05 \\
0.05\end{array}$ & $\begin{array}{l}-0.081 \\
0.042 \\
-0.019\end{array}$ & $\begin{array}{l}0.0533 \\
0.0384 \\
0.0328\end{array}$ & $\begin{array}{l}-0.186 \\
-0.033 \\
-0.084\end{array}$ & $\begin{array}{l}0.024 \\
0.118 \\
0.046\end{array}$ & $\begin{array}{l}\text { Yes } \\
\text { Yes } \\
\text { Yes }\end{array}$ & $\begin{array}{l}\text { Yes } \\
\text { Yes } \\
\text { Yes }\end{array}$ \\
\hline Limbal redness & $\begin{array}{l}\text { Hyperopes } \\
\text { Myopes } \\
\text { Overall }\end{array}$ & $\begin{array}{l}0.05 \\
0.05 \\
0.05\end{array}$ & $\begin{array}{l}-0.012 \\
0.037 \\
0.012\end{array}$ & $\begin{array}{l}0.0533 \\
0.0384 \\
0.0328\end{array}$ & $\begin{array}{l}-0.117 \\
-0.039 \\
-0.052\end{array}$ & $\begin{array}{l}0.093 \\
0.112 \\
0.077\end{array}$ & $\begin{array}{l}\text { Yes } \\
\text { Yes } \\
\text { Yes }\end{array}$ & $\begin{array}{l}\text { Yes } \\
\text { Yes } \\
\text { Yes }\end{array}$ \\
\hline
\end{tabular}

Notes: Non-inferiority is established if the upper confidence limit is less than I grade. Equivalence is established if the upper and lower confidence limits are between \pm I grade. Abbreviations: LS-Mean, least-square means (Day 28 - Baseline); StdErr, standard error; Cl, confidence limits. 
Table 6 Least square (LS) mean difference estimates and 95\% confidence intervals (CI) of graded lid wiper epitheliopathy

\begin{tabular}{|l|l|l|l|l|l|l|l|l|}
\hline & Subject group & $\begin{array}{l}\text { Alpha } \\
\text { level }\end{array}$ & $\begin{array}{l}\text { LS-Mean } \\
\text { difference }\end{array}$ & StdErr & Lower Cl & Upper Cl & $\begin{array}{l}\text { Non-inferiority } \\
\text { Met? }\end{array}$ & $\begin{array}{l}\text { Equivalence } \\
\text { Met? }\end{array}$ \\
\hline \multirow{2}{*}{ LWE } & Hyperopes & 0.05 & 0.107 & 0.2430 & -0.385 & 0.600 & Yes & Yes \\
& Myopes & 0.05 & 0.300 & 0.1819 & -0.068 & 0.668 & Yes & Yes \\
& Overall & 0.05 & 0.204 & 0.1518 & -0.104 & 0.511 & Yes & Yes \\
\hline
\end{tabular}

Notes: Non-inferiority is established if the upper confidence limit is less than I grade. Equivalence is established if the upper and lower confidence limits are between \pm I grade. Abbreviations: LS-Mean, least-square means (Day 28 - Baseline); StdErr, standard error; Cl, confidence limits.

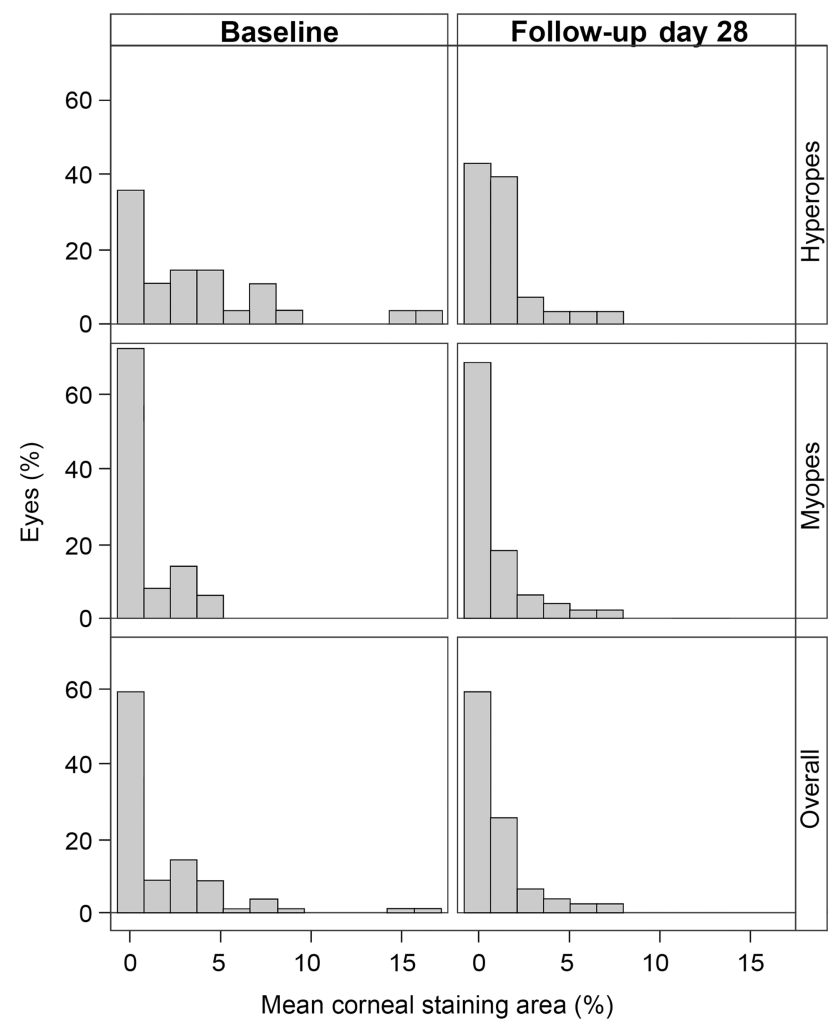

Figure 3 Frequency (\%) of graded mean corneal staining area (\%).

responses in myopic and hyperopic lens wear (due to differences in lens thickness), the study outcome variables were simultaneously analyzed in each subject group.

Corneal swelling/thickening is one of the main indices of corneal physiological change from deficient oxygen metabolism. ${ }^{57,58}$ Previous studies for open-eye contact lens wear showed $2-4.8 \%$ average central corneal swelling ( 11-26 $\mu \mathrm{m}$ central thickening) and a maximum average peripheral swelling of 3.3\% $(\sim 22 \mu \mathrm{m})$ with hydrogel lenses of low oxygen transmissibility. ${ }^{5-61}$ A recent study from our group $^{51}$ showed central swelling of $0.2 \%$ (or $\sim 1.1 \mu \mathrm{m}$ ) and peripheral swelling of $1 \%$ (or $\sim 6.7 \mu \mathrm{m}$ ) with open-eye wear of 1-Day Acuvue Moist DD (also manufactured from etafilcon A) hydrogel lenses. In this current study, similarly, we were unable to measure any clinically significant amounts of corneal swelling after 4 weeks of DD wear of the study etMF lens compared to habitual SiHy CL wear at baseline. This was true for the change in both central thickness $(3.6 \mu \mathrm{m}$ of average thickening in either hyperopic or myopic group) and peripheral corneal thickness (3.0 and $6.4 \mu \mathrm{m}$ of average peripheral thickening in hyperopes and myopes, respectively) (Figure 1). This finding is not unexpected, because manufacturer's published central $\mathrm{Dk} / \mathrm{t}$ of 25.5 units for the etafilcon $\mathrm{A} \mathrm{MF} /$ test lens meets the suggested minimum criterion of 20-24 Dk/t units for daily wear in the central corneal region from the literature. ${ }^{5,61,62}$

The lower differential peripheral corneal thickness (Day 28 - baseline) in the hyperopic group $(3.0 \mu \mathrm{m})$ compared to the myopic group $(6.4 \mu \mathrm{m})$ in the current study (Table 4$)$ can be explained by greater peripheral oxygen performance of plus powered lenses from their expected thinner peripheral thickness profile. However, the $3.4 \mu \mathrm{m}$ average difference between peripheral corneal thickening in the myopic and hyperopic groups on day 28 is clinically insignificant, as we did not find any associated statistically or clinically significant difference in limbal hyperemia between the two groups. Limbal hyperemia is regarded as a sign of peripheral corneal oxygen deficiency with open-eye contact lens wear, ${ }^{63}$ as limbal hyperemia can be eliminated by using highly oxygen transmissible SiHy lenses. ${ }^{14,63,64}$ The results of our current study showed that the change in bulbar and limbal hyperemia in either the hyperopic or myopic study group was $< \pm 0.1$ grade (on a $0-4$ scale) by Oculus K5M (Table 5). This small amount of objectively measured change in ocular hyperemia after 4 weeks of switching to study hydrogel DD lenses was not only statistically insignificant but also clinically irrelevant, as the differential hyperemia was far below the suggested criterion of $\geq 0.40$ grade (on a $0-4$ hyperemia scale) for clinical significance. ${ }^{65}$ The hyperemia results of this study are in line with findings from our recent DD study ${ }^{51}$ that showed a maximum increase in average subjective graded limbal or bulbar hyperemia of $\leq 0.10$ grade (on a $0-4$ scale) after $8 \mathrm{hrs}$ of 
etafilcon A DD wear compared to no lens wear, which was also considered clinically insignificant.

We were also unable to find any clinically significant differences in the subjective grading of LWE score (Table 6) or corneal staining area (\%) (Figure 3) after 28 days of switching to etMF DD wear in the current study. Descriptive analysis of the mean corneal staining area showed that after approximately 1 month of the test lens being worn on a DD basis there were no overall clinically significant differences in corneal staining area compared with the habitual SiHy lens at baseline (Figure 3, bottom). The same was also true in either subject group (hyperopia/myopia), although the maximum graded mean corneal staining in the hyperopic group on day 28 was 9\% less than with the habitual SiHy lenses at the baseline (Figure 3, top).

Previous reports showed a high prevalence of clinical signs such as corneal staining, conjunctival hyperemia, tear film instability and symptoms of dryness, irritation, and reduced comfort and comfortable wearing time with reusable soft lens wear, and that switching to a DD modality may reduce the rate of some of these clinical problems. $^{66,67}$ This study switched patients from a reusable SiHy lens (with the exception of 3 subjects) into a DD hydrogel lens, thus avoiding potential issues associated with the uptake and release of solution-based preservatives $^{68,69}$ and subsequent solution-induced corneal staining. ${ }^{70,71}$ Avoidance of solutions may have contributed to any reductions in staining or hyperemia reported.

Switching to a DD modality may be beneficial to patients who seek convenience, want occasional lens wear or are at risk of developing complications due to noncompliance with regular lens replacement or their care system. In this study, switching from habitual reusable SiHy lens wear to a hydrogel MF DD resulted in minimal corneal physiological impact in either myopes or hyperopes, as measured by clinically insignificant differences in corneal thickness ${ }^{51,61}$ and limbal and bulbar hyperemia $^{65,72}$ after 4 weeks of open-eye wear. The minimal impact of the study lenses on corneal physiology is further supported by the presence of clinically insignificant levels of LWE and corneal staining.

The purpose of this study was not to advocate switching current SiHy MF wearers to hydrogel MFs of lower oxygen performance. The goal of this study was to understand the potential physiological consequences of refitting a patient who, for any reason, would be more suited to wearing a DD hydrogel MF lens, whether that be due to comfort or visual reasons. This is a realistic clinical possibility, as clinicians fitting MF lenses are aware. Analysis of the objective physiological outcomes in our study showed that switching from a reusable SiHy lens to the DD hydrogel MF lenses did not adversely impact ocular physiology in daily wear, despite their lower oxygen transmissibility, over a 4-week period. In light of the absence of any other reports in the literature on the ocular physiological outcomes of refitting current SiHy wearers with hydrogels, the novel findings may help to make the relevant clinical decisions on available different lens options more informed.

In conclusion, no clinically significant differences in a variety of physiological responses were found when habitual reusable SiHy daily wear subjects were refitted into hydrogel etMF, when the subjects were followed for 4 weeks. This study had some limitations, the major one being that it was not randomized and could not be masked. However, we used objective measures of corneal thickness and ocular redness to measure the main physiological outcome variables of this study. This was also a short-term study which was limited to approximately 1 month. A recent retrospective study in a total of 200 subjects (in parallel groups ${ }^{73}$ comparing DD hydrogel and DD SiHy single vision CLs for a 3-month period found similar conclusions to our study. Further long-term studies are required to verify whether the clinical similarities in physiological responses between open-eye wear of DD hydrogel MF and SiHy lenses can hold true for a longer period.

\section{Acknowledgments}

This study was supported by Johnson \& Johnson Vision. Over the past year, CORE has received research grants from Alcon, Allergan, CooperVision, GLChemtech, Johnson \& Johnson Vision, Menicon, Novartis, PS Therapy, Shire and Sightglass outside the submitted work. This work was presented in part as a poster at the American Academy of Optometry annual meeting, November 2016 in Anaheim, CA, USA.

\section{Disclosure}

Thomas Karkkainen and Jing $\mathrm{Xu}$ are employees of Johnson \& Johnson Vision. Thomas Karkkainen also has patents 8,992,012, 8,393,73 and 7,753,521 licensed to Johnson \& Johnson Vision. Lyndon Jones has received personal fees from Alcon, CooperVision, Johnson \& Johnson Vision, Menicon, Novartis and Ophtecs outside the submitted work. The authors report no other conflicts of interest in this work. 


\section{References}

1. Holden BA. The Glenn A. Fry award lecture 1988: the ocular response to contact lens wear. Optom Vis Sci. 1989;66(11):717-733.

2. Klyce SD. Stromal lactate accumulation can account for corneal oedema osmotically following epithelial hypoxia in the rabbit J Physiol. 1981;321:49-64. doi:10.1113/jphysiol.1981.sp013971

3. Liesegang TJ. Physiologic changes of the cornea with contact lens wear. Clao J. 2002;28(1):12-27.

4. Sweeney DF. Have silicone hydrogel lenses eliminated hypoxia? Eye Contact Lens. 2013;39(1):53-60. doi:10.1097/ICL.0b013e31827c7899

5. Holden BA, Mertz GW. Critical oxygen levels to avoid corneal edema for daily and extended wear contact lenses. Invest Ophthalmol Vis Sci. 1984;25(10):1161-1167.

6. Fatt I, Bieber MT. The steady-state distribution of oxygen and carbon dioxide in the in vivo cornea. I. The open eye in air and the closed eye. Exp Eye Res. 1968;7(1):103-112.

7. Sweeney D, Keay L, Jalbert I, et al. Clinical performance of silicone hydrogel lenses. In: Sweeney D, editor. Silicone Hydrogels. The Rebirth of Continuous Wear Contact Lenses. Oxford: ButterworthHeinemann; 2000:90-149.

8. Stapleton F, Keay L, Edwards K, Holden B. The epidemiology of microbial keratitis with silicone hydrogel contact lenses. Eye Contact Lens. 2013;39(1):79-85. doi:10.1097/ICL.0b013e3182713919

9. Morgan PB, Woods CA, Tranoudis IG, et al. International contact lens prescribing in 2018. Contact Lens Spectr. 2019;34(1):26-32.

10. Keay L, Sweeney DF, Jalbert I, Skotnitsky C, Holden BA. Microcyst response to high $\mathrm{Dk} / \mathrm{t}$ silicone hydrogel contact lenses. Optom Vis Sci. 2000;77(11):582-585.

11. Du Toit R, Simpson TL, Fonn D, Chalmers RL. Recovery from hyperemia after overnight wear of low and high transmissibility hydrogel lenses. Curr Eye Res. 2001;22(1):68-73.

12. Sweeney DF. Clinical signs of hypoxia with high-Dk soft lens extended wear: is the cornea convinced? Eye Contact Lens. 2003;29 (1 Suppl):S22-S25. doi:10.1097/00140068-200301001-00007

13. Jalbert I, Stretton S, Naduvilath T, Holden B, Keay L, Sweeney D. Changes in myopia with low-Dk hydrogel and high-Dk silicone hydrogel extended wear. Optom Vis Sci. 2004;81(8):591-596.

14. Dumbleton K, Keir N, Moezzi A, Feng Y, Jones L, Fonn D. Objective and subjective responses in patients refitted to daily-wear silicone hydrogel contact lenses. Optom Vis Sci. 2006;83 (10):758-768. doi:10.1097/01.opx.0000237547.35542.b8

15. Sweeney D, Du Toit R, Keay L, et al. Clinical performance of silicone hydrogel lenses. In: Sweeney D, editor. Silicone Hydrogels: Continuous Wear Contact Lenses, 2nd. Oxford: ButterworthHeinemann; 2004:164-216.

16. Steele KR, Szczotka-Flynn L. Epidemiology of contact lens-induced infiltrates: an updated review. Clin Exp Optom. 2017;100 (5):473-481. doi:10.1111/cxo.12598

17. Szczotka-Flynn L, Diaz M. Risk of corneal inflammatory events with silicone hydrogel and low dk hydrogel extended contact lens wear: a meta-analysis. Optom Vis Sci. 2007;84(4):247-256. doi:10.1097/ OPX.0b013e3180421c47

18. Radford CF, Minassian D, Dart JK, Stapleton F, Verma S. Risk factors for nonulcerative contact lens complications in an ophthalmic accident and emergency department: a case-control study. Ophthalmology. 2009;116(3):385-392. doi:10.1016/j.ophtha.2008.09.053

19. Chalmers RL, Wagner H, Mitchell GL, et al. Age and other risk factors for corneal infiltrative and inflammatory events in young soft contact lens wearers from the Contact Lens Assessment In Youth (CLAY) study. Invest Ophthalmol Vis Sci. 2011;52(9):6690-6696. doi:10.1167/iovs.10-7018

20. Sankaridurg P, de la Jara PL, Holden B. The future of silicone hydrogels. Eye Contact Lens. 2013;39(1):125-129. doi:10.1097/ ICL.0b013e31827d1297
21. Morgan PB, Efron N. Influence of practice setting on contact lens prescribing in the United Kingdom. Cont Lens Anterior Eye. 2015;38 (1):70-72. doi:10.1016/j.clae.2014.07.014

22. Jones D, Woods C, Jones L, Efron N, Morgan P. A sixteen year survey of Canadian contact lens prescribing. Cont Lens Anterior Eye. 2016;39(6):402-410. doi:10.1016/j.clae.2016.09.002

23. Efron N, Nichols JJ, Woods CA, Morgan PB. Trends in US contact lens prescribing 2002 to 2014. Optom Vis Sci. 2015;92(7):758-767. doi:10.1097/OPX.0000000000000623

24. Keir N, Jones L. Wettability and silicone hydrogel lenses: a review. Eye Contact Lens. 2013;39(1):100-108. doi:10.1097/ICL.0b013e31827d546e

25. Walther H, Lorentz H, Heynen M, Kay L, Jones LW. Factors that influence in vitro cholesterol deposition on contact lenses. Optom Vis Sci. 2013;90(10):1057-1065. doi:10.1097/OPX.0000000000000022

26. Nichols JJ. Deposition on silicone hydrogel lenses. Eye Contact Lens. 2013;39(1):19-22. doi:10.1097/ICL.0b013e318275305b

27. Maissa C, Guillon M, Cockshott N, Garofalo RJ, Lemp JM, Boclair JW. Contact lens lipid spoliation of hydrogel and silicone hydrogel lenses. Optom Vis Sci. 2014;91(9):1071-1083. doi:10.1097/ OPX.0000000000000341

28. Patel S, Farrell JC. Age-related changes in precorneal tear film stability. Optom Vis Sci. 1989;66(3):175-178.

29. Maissa C, Guillon M. Tear film dynamics and lipid layer characteristics-effect of age and gender. Cont Lens Anterior Eye. 2010;33 (4):176-182. doi:10.1016/j.clae.2010.02.003

30. Guillon M. Are silicone hydrogel contact lenses more comfortable than hydrogel contact lenses? Eye Contact Lens. 2013;39(1):86-92. doi:10.1097/ICL.0b013e31827cb99f

31. Jones L, Brennan NA, González-Méijome J, et al. The TFOS international workshop on contact lens discomfort: report of the contact lens materials, design, and care subcommittee. Invest Ophthalmol Vis Sci. 2013;54(11):TFOS37-TFOS70. doi:10.1167/iovs.13-13215

32. Ozkan J, Willcox MD. The effect of lens modulus on insertion comfort with silicone hydrogel lenses. Invest Ophthalmol Vis Sci. 2011;52(14):6515-6515.

33. Maissa C, Guillon M, Garofalo RJ. Contact lens-induced circumlimbal staining in silicone hydrogel contact lenses worn on a daily wear basis. Eye Contact Lens. 2012;38(1):16-26. doi:10.1097/ ICL.0b013e31823bad46

34. Tighe BJ. A decade of silicone hydrogel development: surface properties, mechanical properties, and ocular compatibility. Eye Contact Lens. 2013;39(1):4-12. doi: 10.1097/ICL.0b013e318275452b

35. Sorbara L, Maram J, Simpson T, Hutchings N. Corneal, conjunctival effects and blood flow changes related to silicone hydrogel lens wear and their correlations with end of day comfort. Cont Lens Anterior Eye. 2018;41(2):193-200. doi: 10.1016/j.clae.2017.12.010

36. Montes-Mico R, Madrid-Costa D, Dominguez-Vicent A, BeldaSalmeron L, Ferrer-Blasco T. In vitro power profiles of multifocal simultaneous vision contact lenses. Cont Lens Anterior Eye. 2014;37 (3):162-167. doi:10.1016/j.clae.2013.09.014

37. Dominguez-Vicent A, Marin-Franch I, Esteve-Taboada JJ, MadridCosta D, Montes-Mico R. Repeatability of in vitro power profile measurements for multifocal contact lenses. Cont Lens Anterior Eye. 2015;38(3):168-172. doi:10.1016/j.clae.2015.01.013

38. Madrid-Costa D, Ruiz-Alcocer J, Garcia-Lazaro S, Ferrer-Blasco T, Montes-Mico R. Optical power distribution of refractive and aspheric multifocal contact lenses: effect of pupil size. Cont Lens Anterior Eye. 2015;38(5):317-321. doi:10.1016/j.clae.2015.03.008

39. Wagner S, Conrad F, Bakaraju RC, Fedtke C, Ehrmann K, Holden BA. Power profiles of single vision and multifocal soft contact lenses. Cont Lens Anterior Eye. 2015;38(1):2-14. doi:10.1016/j.clae.2014.07.008

40. Kim E, Bakaraju RC, Ehrmann K. Reliability of power profiles measured on NIMO TR1504 (Lambda-X) and effects of lens decentration for single vision, bifocal and multifocal contact lenses. J Optom. 2016;9(2):126-136. doi:10.1016/j.optom.2015.10.005 
41. Perez-Prados R, Pinero DP, Perez-Cambrodi RJ, Madrid-Costa D. Soft multifocal simultaneous image contact lenses: a review. Clin Exp Optom. 2017;100(2):107-127. doi:10.1111/cxo.12488

42. Sankaridurg P. Contact lenses to slow progression of myopia. Clin Exp Optom. 2017;100(5):432-437. doi:10.1111/cxo.12584

43. Monsalvez-Romin D, Dominguez-Vicent A, Garcia-Lazaro S, Esteve-Taboada JJ, Cervino A. Power profiles in multifocal contact lenses with variable multifocal zone. Clin Exp Optom. 2018;101 (1):57-63. doi:10.1111/cxo.12575

44. Moody KJ, Hickson-Curran S, Wooley B, Ruston D. Innovating for multifocal fitting success. Optician. 2015;249(6509):12-17.

45. Ruston D, Sulley A. Madec-Hily. From science to practice: a new multifocal. Optician. 2016;251(6534):20-25.

46. Birren JE, Casperson RC, Botwinick J. Age changes in pupil size. $J$ Gerontol. 1950;5(3):216-221.

47. Cakmak H, Cagil N, Simavli H, Duzen B, Simsek S. Refractive error may influence mesopic pupil size. Curr Eye Res. 2010;35 (2):130-136. doi:10.3109/02713680903447892

48. Brennan NA, Coles ML, Ang JH. An evaluation of silicone-hydrogel lenses worn on a daily wear basis. Clin Exp Optom. 2006;89 (1):18-25. doi:10.1111/j.1444-0938.2006.00003.x

49. Mandell RB, Fatt I. Thinning of the human cornea on awakening. Nature. 1965;208(5007):292-293

50. Mertz GW. Overnight swelling of the living human cornea. $J \mathrm{Am}$ Optom Assoc. 1980;51(3):211-214.

51. Moezzi AM, Varikooty J, Schulze M, et al. Corneal swelling with cosmetic etafilcon a lenses versus no lens wear. Optom Vis Sci. 2016;93(6):619-628. doi:10.1097/OPX.0000000000000840

52. Jerchel NN, Sickenberger W, Schulze MM. Objective classification and documentation of bulbar redness using a corneal topographer. Cont Lens Anterior Eye. 2012;35:e18. doi:10.1016/j.clae.2012.08.058

53. Caffery BE, Josephson JE. Corneal staining after sequential instillations of fluorescein over 30 days. Optom Vis Sci. 1991;68(6):467-469.

54. Cox I, Fonn D. Interference filters to eliminate the surface reflex and improve contrast during fluorescein photography. Int Contact Lens Clin. 1991;18(9/10):178-181. doi:10.1016/0892-8967(91)90004-J

55. Jones L. Disposable contact lenses - a review of currently available systems. Optician. 1995;209(5500):16-22.

56. Cho P, Boost MV. Daily disposable lenses: the better alternative. Cont Lens Anterior Eye. 2013;36(1):4-12. doi:10.1016/j. clae.2012.10.073

57. Bruce AS, Brennan NA. Corneal pathophysiology with contact lens wear. Surv Ophthalmol. 1990;35(1):25-58.

58. Fonn D, Sweeney D, Holden BA, Cavanagh D. Corneal oxygen deficiency. Eye Contact Lens. 2005;31(1):23-27. doi:10.1097/01. ICL.0000151949.30730.9D

59. Weissman BA, Blaze PA, Ingles S, Wheeler N. Open-eye corneal swelling secondary to hydrogel contact lens wear. Am J Optom Physiol Opt. 1988;65(4):272-276.
60. La Hood D. Daytime edema levels with plus powered low and high water content hydrogel contact lenses. Optom Vis Sci. 1991;68 (11):877-880

61. Morgan PB, Brennan NA, Maldonado-Codina C, Quhill W, Rashid K, Efron N. Central and peripheral oxygen transmissibility thresholds to avoid corneal swelling during open eye soft contact lens wear. J Biomed Mater Res B Appl Biomater. 2010;92(2):361-365. doi:10.1002/jbm.b.31522

62. Brennan NA. Beyond flux: total corneal oxygen consumption as an index of corneal oxygenation during contact lens wear. Optom Vis Sci. 2005;82(6):467-472.

63. Papas EB, Vajdic CM, Austen R, Holden BA. High-oxygentransmissibility soft contact lenses do not induce limbal hyperaemia. Curr Eye Res. 1997;16(9):942-948.

64. Dumbleton K, Keir N, Moezzi AM, Jones L, Fonn D. Redness, dryness and comfort following refitting long term low Dk hydrogel wearers with silicone hydrogels. Optom Vis Sci. 2004;81(Suppl.):31.

65. Murphy PJ, Lau JS, Sim MM, Woods RL. How red is a white eye? Clinical grading of normal conjunctival hyperaemia. Eye (Lond). 2007;21(5):633-638. doi:10.1038/sj.eye.6702295

66. Riley C, Young G, Chalmers R. Prevalence of ocular surface symptoms, signs, and uncomfortable hours of wear in contact lens wearers: the effect of refitting with daily-wear silicone hydrogel lenses (senofilcon a). Eye Contact Lens. 2006;32(6):281-286. doi:10.1097/01. icl.0000224522.04723.7a

67. Hickson-Curran S, Spyridon M, Hunt C, Young G. The use of daily disposable lenses in problematic reusable contact lens wearers. Cont Lens Anterior Eye. 2014;37(4):285-291. doi:10.1016/j. clae.2014.03.002

68. Powell CH, Lally JM, Hoong LD, Huth SW. Lipophilic versus hydrodynamic modes of uptake and release by contact lenses of active entities used in multipurpose solutions. Cont Lens Anterior Eye. 2010;33(1):9-18. doi:10.1016/j.clae.2009.10.006

69. Jones L, Powell CH. Uptake and release phenomena in contact lens care by silicone hydrogel lenses. Eye Contact Lens. 2013;39 (1):29-36. doi:10.1097/ICL.0b013e31827d4f25

70. Jones L, MacDougall N, Sorbara LG. Asymptomatic corneal staining associated with the use of balafilcon silicone-hydrogel contact lenses disinfected with a polyaminopropyl biguanide-preserved care regimen. Optom Vis Sci. 2002;79(12):753-761.

71. Andrasko G, Ryen K. A series of evaluations of MPS and silicone hydrogel lens combinations. Rev Cornea Cont Lenses. 2007;143:36-42.

72. Pult H, Murphy PJ, Purslow C, Nyman J, Woods RL. Limbal and bulbar hyperaemia in normal eyes. Ophthalmic Physiol Opt. 2008;28 (1):13-20. doi:10.1111/j.1475-1313.2007.00534.x

73. Diec J, Tilia D, Thomas V. Comparison of silicone hydrogel and hydrogel daily disposable contact lenses. Eye Contact Lens. 2018;44 (Suppl 1):S167-S172. doi: 10.1097/ICL.0000000000000363
Clinical Ophthalmology

\section{Publish your work in this journal}

Clinical Ophthalmology is an international, peer-reviewed journal covering all subspecialties within ophthalmology. Key topics include: Optometry; Visual science; Pharmacology and drug therapy in eye diseases; Basic Sciences; Primary and Secondary eye care; Patient Safety and Quality of Care Improvements. This journal is indexed on PubMed
Central and CAS, and is the official journal of The Society of Clinical Ophthalmology (SCO). The manuscript management system is completely online and includes a very quick and fair peer-review system, which is all easy to use. Visit http://www.dovepress.com/ testimonials.php to read real quotes from published authors. 